\title{
Diagnostic and Therapeutic Strategies for Peritoneal Tuberculosis: A Review
}

\author{
David C. Wu, Leon D. Averbukh* and George Y. Wu \\ Department of Medicine, Division of Gastroenterology-Hepatology, University of Connecticut Health Center, Farmington, CT, USA
}

\begin{abstract}
Peritoneal tuberculosis (PTB), although rarer than its pulmonary counterpart, is a serious health concern in regions of the world with high tuberculosis prevalence. Individuals with baseline immunocompromise condition, whether acquired or medically induced, are at greatest risk for experiencing PTB. While medical treatment of the condition is similar to that of the pulmonary disease, the generally immunocompromised state of those infected with PTB, along with a lack of highly sensitive and specific testing methods make early diagnosis difficult. This review discusses the risks factors, clinical features, diagnostic methods, and treatment options for PTB. Citation of this article: Wu DC, Averbukh LD, Wu GY. Diagnostic and therapeutic strategies for peritoneal tuberculosis: A review. J Clin Transl Hepatol 2019;7(2):140-148. doi: 10.14218/JCTH.2018.00062.
\end{abstract}

\section{Introduction}

Tuberculosis (TB) therapy and the generally improving socioeconomic status worldwide have decreased the burden of TB. However, one-fourth of the world's population continues to be infected with TB. ${ }^{1}$ Regions of southeast Asia, the Western Pacific and sub-Saharan Africa remain particularly affected. While most cases of TB are pulmonary, the rate of abdominal cavity infection and its contents, identified as abdominal TB, appears to be rising and is currently the 6th most common extrapulmonary site for TB infection. ${ }^{2}$ TB of the peritoneum (PTB) accounts for about $25-50 \%$ of abdominal TB cases and $0.1-0.7 \%$ of all TB cases. ${ }^{3}$

The rising prevalence of abdominal TB, and along with it PTB, is thought to be secondary to the increasing prevalence of immunocompromised states, including human immunodeficiency virus (HIV) infection and alcoholic liver disease, as well as of increased migration into endemic regions. ${ }^{4,5}$ PTB most commonly affects those between the ages of 35-45

Keywords: Peritoneal tuberculosis; Tuberculosis; Liver disease; Human immunodeficiency virus.

Abbreviations: ADA, adenosine deaminase; AIDS, autoimmune deficiency syndrome; HIV, human immunodeficiency virus; IGRA, interferon gamma release assay; INH, isoniazid; MCP-1, monocyte chemoattractant protein-1; PTB, peritoneal tuberculosis; QFT-GIT, quantiferon gold-TB gold in-tube; RIF, rifampin; SAAG, serum-ascites albumin gradient; TB, tuberculosis; $T N F \alpha$, tumor necrosis factor alpha; TLR, Toll-like receptor.

Received: 12 December 2018; Revised: 8 March 2019; Accepted: 14 March 2019 *Correspondence to: Leon D. Averbukh, Department of Medicine, Division of Gastroenterology-Hepatology, University of Connecticut Health Center, 236 Farmington Ave., Farmington, CT 06030, USA. Tel: +1-347-306-4752, Fax: +1-860679-4613, E-mail: averbukh@uchc.edu with equal rates amongst both sexes and has a strong correlation with lower socioeconomic status, poor hygiene, and overcrowding. ${ }^{6}$ In this review, we discuss the clinical features, pathogenesis, diagnostic techniques, and therapy for PTB, a specific subtype of abdominal TB affecting the peritoneum.

\section{Clinical features}

PTB is difficult to diagnose clinically, given its nonspecific features that often overlap with many other chronic conditions, such as liver cirrhosis and autoimmune deficiency syndrome (commonly known as AIDS). Classically, PTB presents as one of three different variants: wet-ascitic, fibrotic-fixed, and dry plastic. ${ }^{7}$ The wet-ascitic type is defined by large amounts of loculated or high protein ascitic fluid. The fibrotic type is characterized by interloped adhesions of bowel along the omentum and mesentery. The dry plastic type is characterized by a gross inflammatory reaction demonstrated by diffuse fibrous adhesions and nodules all along the peritoneum. It should be noted, however, that PTB can present as a combination of these three variants.

On presentation, there is significant variability in symptom onset and duration, ranging from several weeks to months. Most commonly, patients present with signs and symptoms of vague abdominal pain, weight loss, fever, abdominal ascites, abdominal distension, abdominal mass, and abdominal tenderness $^{7-12}$ (Table 1 ).

Table 1. Literature $8,10,11,37,39,44,75-85$ review of commonly described symptoms and signs of PTB

\begin{tabular}{ll}
\hline Characterization & Total/ Avg frequency \\
\hline Number of cases & 1725 \\
Symptoms & \\
$\quad$ Abdominal pain & $75.0 \%$ \\
$\quad$ Weight loss & $53.0 \%$ \\
Signs & \\
Fever & $69.0 \%$ \\
ascites & $62.0 \%$ \\
Abdominal distension & $60.0 \%$ \\
Abdominal mass & $34.0 \%$ \\
Abdominal tenderness & $49.0 \%$ \\
\hline
\end{tabular}




\section{Susceptibility and mechanisms of pathogenesis}

Most commonly, PTB develops as a result of reactivation of latent TB. The pathologic mechanism involves the activation of localized tuberculous focus in the peritoneum created by the hematogenous spread of bacteria from the primary pulmonary focus by mesenteric lymph nodes during prior infection. PTB can less commonly develop in the setting of active pulmonary of miliary TB by the same mechanism ${ }^{13}$ (Figs. 1 and 2). Alternative routes of infection include ingestion of bacilli with subsequent passage to mesenteric lymph nodes through the Peyer's patches in intestinal mucosa as well as contiguous spread from infected lymph nodes, ileocecal TB, or genitourinary TB. ${ }^{14}$ Although very rare, PTB caused by Mycobacterium bovis rather than M. tuberculosis has been noted to occur following the ingestion of unpasteurized milk. ${ }^{15}$

\section{Infectious disease: HIV}

$\mathrm{HIV}$ is one of the most significant risk factors for the development of both pulmonary and extrapulmonary TB. Up to $50 \%$ of patients with active TB who are HIV positive develop extrapulmonary manifestations, as compared to only $10-$ $15 \%$ of those who have active TB but are HIV negative. ${ }^{16}$ Clinically important is the finding that PTB in patients with untreated HIV may be relatively asymptomatic and can go undiagnosed due to the patient's inability to mount an immune response. In one case report, a patient's PTB was diagnosed only after experiencing immune reconstitution syndrome following initiation of antiretroviral therapy for HIV. ${ }^{17}$ The mechanism behind the increased susceptibility for PTB in HIV patients lies in the impairment of the T-helper cell 1-type immune response, a crucial part of the adaptive immune system for TB defense. ${ }^{18}$

\section{Immunomodulating medications}

Immunomodulating medications have been implicated as significant risk factors for PTB. Patients on tumor necrosis factor alpha (TNF $\alpha$ ) inhibitor therapy for autoimmune disorders, including Crohn's disease and psoriasis, have been noted to be at risk for TB reactivation. ${ }^{19-21}$ The mechanism behind this reactivation is believed to be due to the role TNF $\alpha$ plays in inducing granuloma formation, thereby controlling bacterial growth and limiting bacterial dissemination and tissue damage during TB infection. With TNF $\alpha$ blocking medications such as infliximab and adalimumab, granuloma formation and maintenance is impaired and the likelihood of disseminated disease increases. ${ }^{19-23}$ Other inflammatory modulating medications, such as corticosteroids, have also been shown to increase the risk of developing PTB. ${ }^{15}$

Pathologic states: Liver cirrhosis, diabetes mellitus, and renal failure requiring dialysis

Liver cirrhosis, diabetes mellitus, and renal failure requiring continuous ambulatory peritoneal dialysis have all been demonstrated to be significant risk factors in the development of PTB. ${ }^{24-26}$ Cirrhotic patients have significantly higher rates of pulmonary TB infection. In one study, the infection rate in cirrhotic patients was found to be nearly 15 times that of the general population. ${ }^{24}$ Additionally, cirrhotic patients are significantly more likely to exhibit extrapulmonary TB (31\% vs.

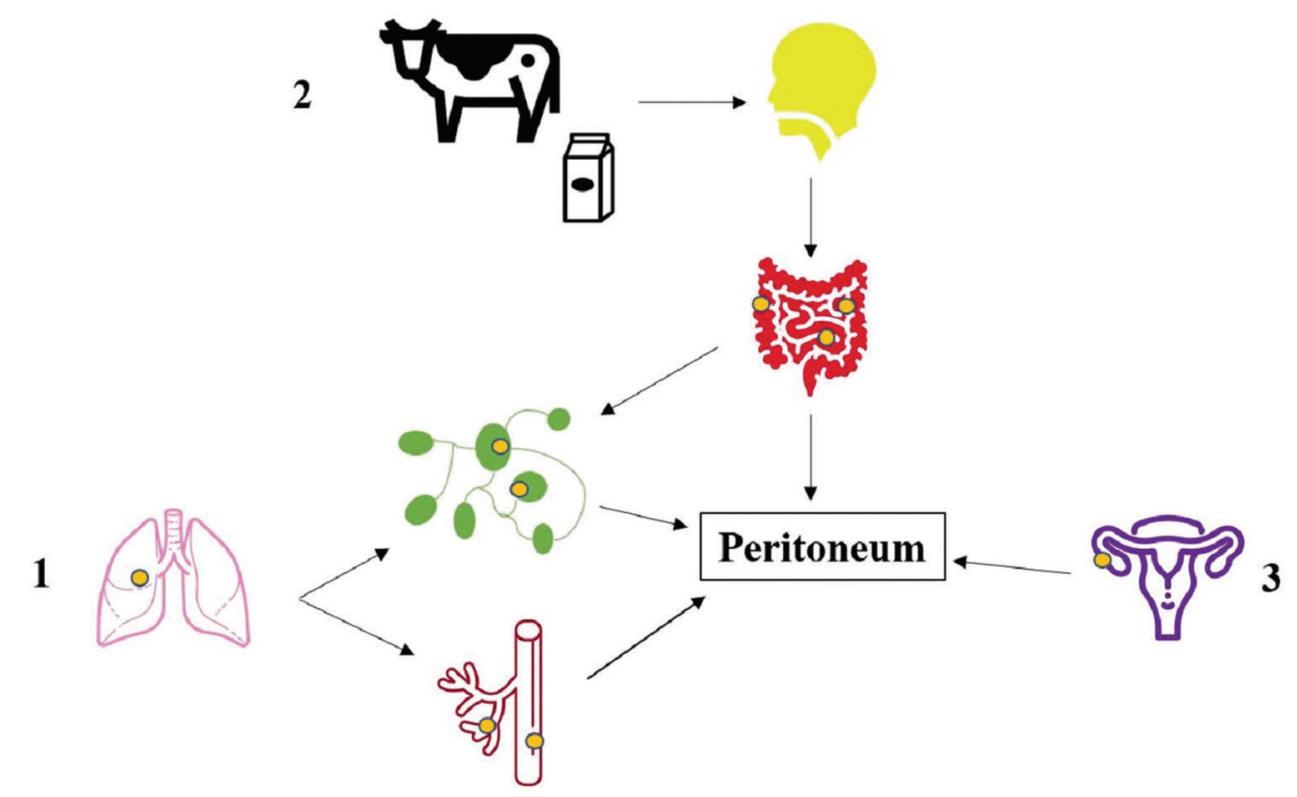

Fig. 1. Mechanisms of PTB development. There are three main pathways through which TB infects the peritoneum. In most cases, the bacterial spread is achieved by reactivation of TB in the lungs (or other solid organs) and subsequent hematogenous or lymphatic spread to the peritoneum (depicted in 1 ). Though rare, peritoneal infection by the intestinal tract is possible due to the ingestion of infected milk or sputum. In this pathway, the TB infects the mucosal layer of the gastrointestinal tract, with subsequent formation of epithelioid tubercles in the lymphoid tissue of the submucosa. Caseous necrosis of the tubercles in roughly $2-4$ weeks leads to mucosal ulceration and can lead to infection of deeper layers of the intestines and eventually into adjacent lymph nodes and peritoneum (depicted in 2). The third pathway of peritoneal infection involves the direct spread to the peritoneum from an infected adjacent focus, such as the fallopian tubes (pictured) or a psoas abscess ${ }^{74}$ (depicted in 3 ). The icons were adapted from flaticon.com. Abbreviations: PTB, peritoneal tuberculosis; TB, tuberculosis. 

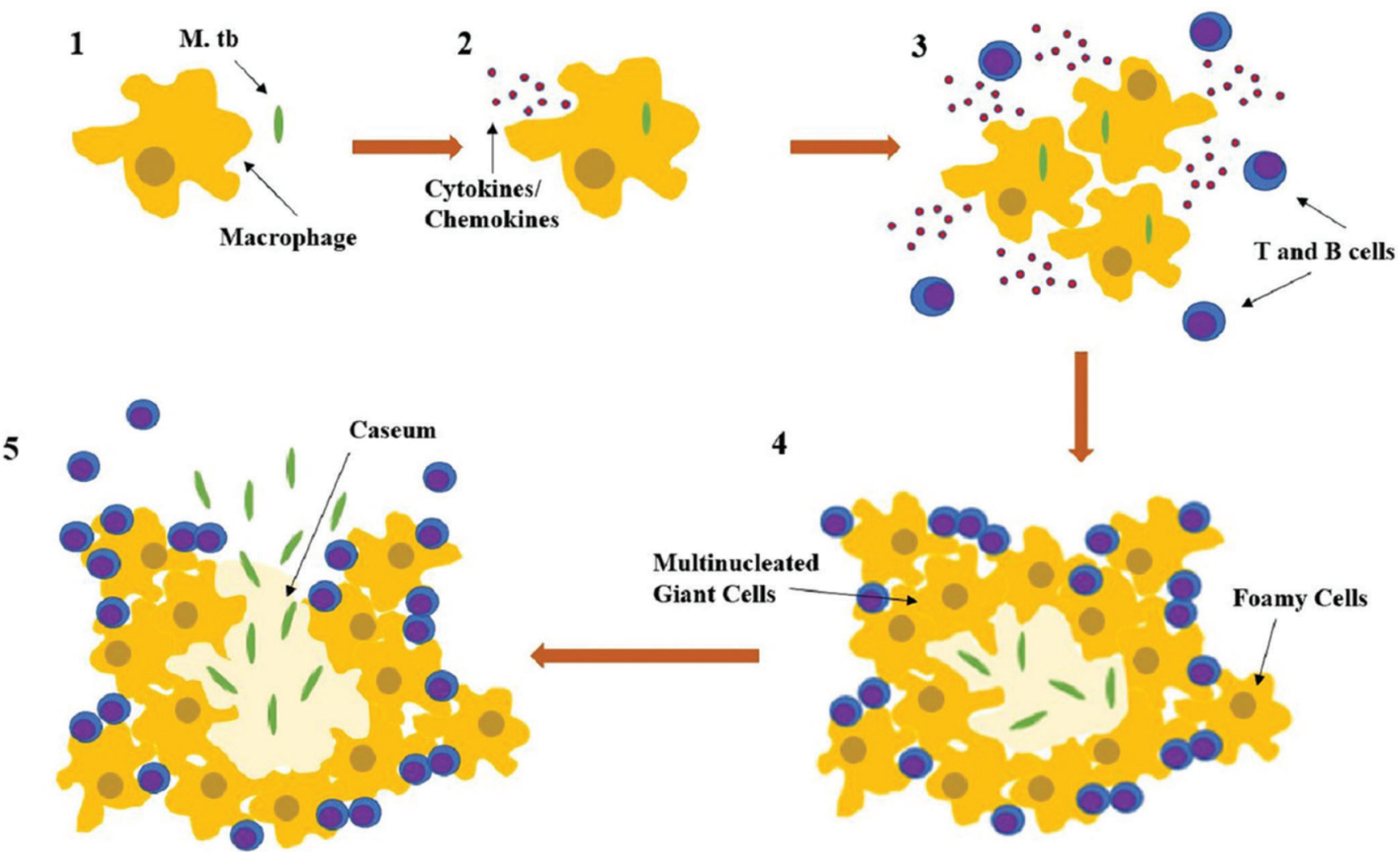

4

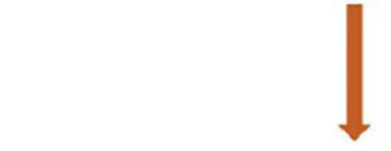

Fig. 2. Formation of the TB granuloma in primary lung infection and subsequent spread. Following the inhalation of contaminated aerosols, Mycobacterium tuberculosis is recognized by macrophages in the lung alveoli by surface receptors (depicted in 1 ). Subsequently, the bacteria are taken up by macrophages which, along with epithelial cells and neutrophils, trigger innate immune signaling pathways that allow for the production of chemokines and cytokines (depicted in 2). The release of chemokines and cytokines recruits more macrophages, lymphocytes, and dendritic cells to the infection site, where they form granulomas composed of infected macrophages in the middle, surrounded by lymphocytes (CD4+, CD8+, gamma/delta T cells). The conglomerated macrophages can also fuse to form multinucleated giant cells or differentiate into lipid rich foamy cells (depicted in 3 and 4). Within the granuloma, bacteria can survive for years, in a latent disease state. However, once triggered by external factors, such as additional immunocompromising states, the bacteria can reactivate, killing the core infected macrophages and, thereby, producing a necrotic zone at the center of the granuloma known as a caseum (depicted in 4). The granulomatous structure weakens with the caseum and eventually breaks down, releasing bacteria through the body by blood, lymph, and infectious aerosolized droplets. Abbreviation: TB, tuberculosis.

$12 \%$ in the general population) with the predominant manifestation being peritoneal. ${ }^{27}$ The etiology of cirrhosis also appears to be important as alcohol abuse and was found to be an underlying cause in up to as many as $90 \%$ of cirrhotic patients with PTB. ${ }^{28}$ The mechanism behind the increased risk of PTB in cirrhosis secondary to alcoholic liver disease is unknown, though it has been hypothesized to involve the cumulative effects of factors not as prominent in nonalcoholic liver disease cases of cirrhosis, such as malnutrition and impaired T cell-dependent function. ${ }^{2}$

Diabetes has been identified as a significant risk factor for PTB susceptibility. In one Taiwanese study, the incidence of PTB in diabetics was as high as $26.7 \%$, as opposed to $6.7 \%$ in nondiabetics. ${ }^{29}$ The reason for an increased risk of PTB in diabetics is believed to involve reduced phagocytic capability of peritoneal macrophages. ${ }^{30}$ Studies involving a murine model showed that among those infected with TB, diabetic mice, when compared to their non-diabetic peers, had significantly higher bacillary loads in the abdominal cavity. The isolated macrophages of the diabetic mice showed lower uptake of mycolic acid-coated beads, reduced bacterial internalization and killing, and altered cytokine responses by $\operatorname{TNF} \alpha$, monocyte chemoattractant protein-1 (commonly known as
MCP-1) and interleukin-6 (commonly known as IL-6). The diabetic mice also displayed more inflammatory lesions than their nondiabetic counterparts. ${ }^{30}$

Patients with end-stage renal failure on continuous ambulatory peritoneal dialysis have been found to be at significantly higher risk for PTB, when compared to the general population, especially in developing countries and south Asia. ${ }^{31}$ Patients with renal failure are at higher risk for PTB secondary to their deficiency in cell-mediated immunity. ${ }^{32}$ Additionally, the dialysis effluent used in continuous ambulatory peritoneal dialysis is bioincompatible due to its increased glucose concentration and nonphysiologic $\mathrm{pH}$, impairing phagocytic and lymphocytic activity in the peritoneum and increasing risk of disseminated infection. ${ }^{32}$

\section{Genetic variables}

Recent studies have found that Toll-like receptors, such as TLR-2, that play a key role in the innate immune system are important in host defense against $M$. tuberculosis. ${ }^{33}$ Polymorphisms of TLR-2 have been shown to significantly impact susceptibility or resistance to TB. ${ }^{34}$ Though these polymorphisms have generally been studied in pulmonary TB, one series 
investigated cases of PTB and found that there was a significant association between the GA genotype (heterozygous mutant) of TLR-2 Arg753GIn polymorphism and the risk of infection with PTB. ${ }^{33}$ This suggests that individuals with genetic polymorphisms of the Arg753Gln portion of TLR-2 may be at increased risk of developing PTB, as compared to those with nonmutant variants. Currently, however, there is no support for polymorphism screening in patients.

\section{Diagnostic methods for PTB}

\section{Hematological tests}

PTB is insidious and difficult to diagnose. Routine hematologic tests are nonspecific, as the most frequent hematologic findings include moderate normochromic normocytic anemia, thrombocytosis, and white blood cell counts within normal limits. ${ }^{14}$

Interferon gamma release assays (IGRAs), such as quantiferon gold-TB gold in-tube (QFT-GIT) and T-spot TB, are in vitro assays that quantify the level of interferon gamma released by T-lymphocytes in a blood sample after exposure to synthetic TB antigen (e.g., ESAT-6) which are normally absent from the bacillus Calmette-Guérin vaccine. These assays are dependent on primary versus secondary immunologic response, in which the second response lymphocytes produce a larger amount of interferon gamma relative to the primary response. Therefore, these tests demonstrate a patient's exposure to TB but are unable to distinguish between latent and active infections. Unfortunately, due to the molecular mechanism behind IGRA testing, the frequently immunocompromised states of those with PTB will likely result in reduced test sensitivities/ indeterminate results.

For these reasons, IGRAs alone are insufficient in diagnosing PTB. In one meta-analysis on extrapulmonary TB, in a total of 1,711 patients in low- and middle-income countries, the pooled sensitivity for QFT-G was only $72 \%$ [95\% CI: $56-$ $79 \%$ ] and $90 \%$ [95\% CI: $86 \%-93 \%$ ] for T-SPOT. ${ }^{35}$ However, if used in conjunction with radiologic and clinical assessments, IGRAs may help increase diagnostic power in those with suspected PTB. ${ }^{36}$

\section{Ascitic fluid tests}

Ascitic fluid analysis is frequently performed for patients with suspected PTB. The most common ascitic fluid tests include acid-fast bacilli stain/smear and culture, white blood cell count, lactate dehydrogenase, serum-ascites albumin gradient (SAAG) score, and cancer antigen-125. Acid-fast bacilli staining and Ziehl-Neelsen staining of aspirated ascitic fluid are generally insensitive up to $3 \%$, while bacterial culture sensitivities range from $21-35 \% .37,38$ In patients with PTB and ascites, ascitic aspirate for white blood cell count varies widely depending on the patient immune status, from as low as 500 to as high as 1500 cells $/ \mathrm{mm}^{3}$. The exception to this finding are patients with renal failure, in whom the predominant ascitic fluid cell type has been reported to be neutrophilic. $2,12,39$ At this time, the discrepancy in cell types between those with renal failure and those without is not well understood.

Within the last 10 years, the role of IGRAs in the diagnosis of PTB in ascitic fluid has gained momentum. In a 2015 metaanalysis, investigators found that the diagnostic accuracy of QFT-GIT with T-SPOT TB was greater in IGRAs of extra- sanguineous body fluid compared with peripheral blood. This is most likely due to the higher concentration of lymphocytes within the body compartments that have the highest TB load. Additionally, these studies found that the T-spot TB test outperformed QFT-GIT in both sensitivity, 95\% with 95\% CI: 92-96, and specificity, $78 \%$ with 95\% CI: 69-85). ${ }^{40}$ However, application of this information for diagnosis of PTB is limited as the sample size of analyzed peritoneal fluid was small compared with extra-pulmonary fluid sources.

\section{Biochemical tests}

Of the biochemical tests conducted on PTB ascitic fluid, lactate dehydrogenase has the highest pooled sensitivity, averaging around $77 \%$. However, lactate dehydrogenase provides a similar sensitivity for other diseases, such as pancreatic ascites and peritoneal carcinomatosis, and therefore does not provide discriminatory value without clinical correlation. ${ }^{41}$

When evaluating ascitic protein levels, a SAAG can be calculated to help differentiate ascites secondary to portal hypertension from nonportal sources. The SAAG is calculated by subtracting the ascitic albumin level from the serum albumin level. A SAAG $<1.1 \mathrm{~g} / \mathrm{L}$ can have up to $100 \%$ sensitivity for ascites of nonportal etiology in patients with PTB and no complicating chronic liver disease. ${ }^{42,43}$ In cases where PTB diagnosis is complicated by chronic liver disease, the sensitivity of this calculation drops significantly to 28$88 \% .{ }^{41,42}$ Unfortunately, in both cases, the specificity of the test remains poor.

Cancer antigen (commonly known as CA)-125 is a sensitive, but nonspecific tumor marker for ovarian carcinoma that has been reported to be increased in PTB. At cutoffs of $35 \mathrm{U} /$ $\mathrm{mL}, \mathrm{CA}-125$ was found to have an average sensitivity of $83.33 \%$ and a specificity of $50 \%$ for PTB. The degree of CA125 increase may be useful in diagnostically differentiating PTB and ovarian carcinoma, although little data exists on the subject at this time. ${ }^{2,43,44}$

Adenosine deaminase (ADA) levels and PCR are newer ascitic molecular diagnostic tools to detect mycobacteria. ADA, an aminohydrolase involved in purine metabolism, is a potent modulator of $\mathrm{T}$ cell differentiation. ${ }^{45}$ Recent studies examining ADA as a molecular marker for PTB found a proportional increase in differentiation of T cells in response to TB antigen. Test sensitivities and specificities were noted to be $>90 \%$ with ascitic ADA levels $>30 \mathrm{U} / \mathrm{L}^{2,8,12,39-48}$

Gene amplification techniques, like real-time PCR, have also shown tremendous potential. The Xpert nested real-time MTB/ rifampin (RIF) PCR (CepheidGeneXpert ${ }^{\circledR}$ System, USA), approved for use by the World Health Organization in 2010, has demonstrated initial sensitivities and specificities as high as $93.7 \%$ and $91.7 \%$, respectively, in cases of pulmonary TB. ${ }^{49}$ In a recent meta-analysis of 4461 samples comparing Xpert MTB/RIF assay with culture or composite standard, the Xpert pooled sensitivity and specificity was demonstrated to be $83.1 \%$ [95\% CI: $71.4-90.7 \%$ ] and $81.2 \%$ [95\% CI: $72.4-$ $87.7 \%]$, respectively. ${ }^{50}$ One study looking at the diagnostic accuracy of Xpert MTB in 16,213 specimens presumed to have EPTB found the pooled Xpert sensitivity to range from $31 \%$ in pleural tissue to $97 \%$ in bone or joint, while the pooled Xpert specificity ranged from $99 \%$ in pleural tissues to $82 \%$ in bone or joint. ${ }^{51}$ The majority of studies support Xpert MTB as an excellent diagnostic test for ruling in EPTB, especially when there is a positive confirmed culture. Unfortunately, it appears 


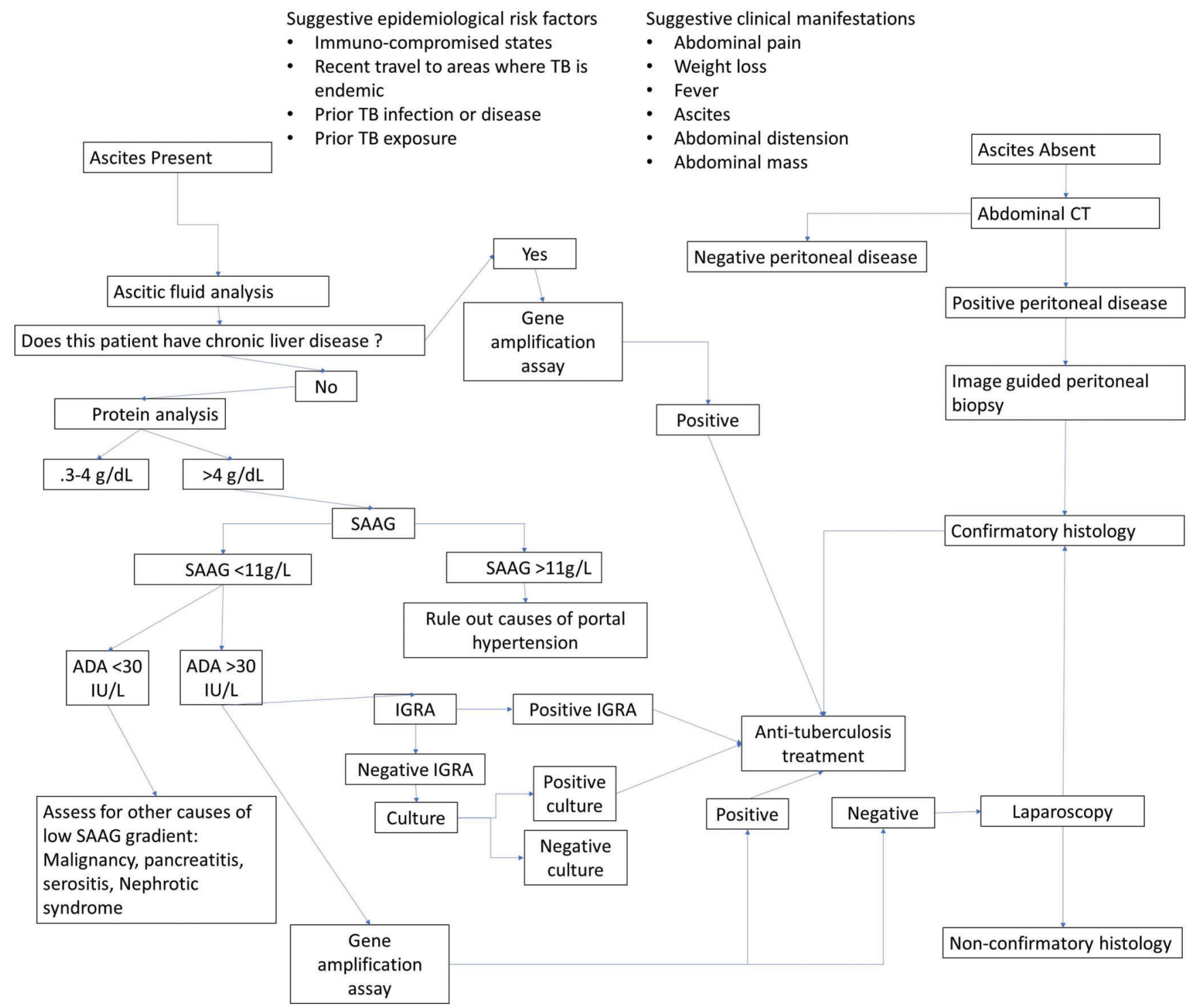

Fig. 3. Proposed algorithm for diagnostic strategies in PTB, adapted and modified from Sinai, 2005. Abbreviation: PTB, peritoneal tuberculosis.

that Xpert MTB may have significant variability in sensitivity relative to the tissue being sampled. ${ }^{50,51}$

Additional studies attempting to improve on the headway made in gene amplification include studies on multiplex PCR with selected gene targets previously determined to have high specificity for TB such as mycobacterial protein 64 and insertion sequence 6110 . In addition to increasing the general sensitivity of the assay, these new targets also have the added benefit of bypassing the high cost of the Xpert assay. In one study comparing the Xpert MTB/RIF assay with multiplex $P C R$ in the detection of TB in suspected pulmonary TB, multiplex PCR had a higher sensitivity and specificity (sensitivity of $100.0 \%$ and specificity of $66.7 \%$ ) than Xpert MTB/RIF (sensitivity of $78.6 \%$ and specificity of $33.3 \%$ ). ${ }^{52}$ A number of other studies looking at multiplex PCR in the diagnosis of extrapulmonary TB suggested a pooled sensitivity of roughly $94.5 \% .^{53-56}$ It should be noted that gene amplification techniques are only as good as the sequence of probes being used, and not all genes being targeted will have the same sequence.

The gold standard for definitive PTB diagnosis remains laparoscopy with peritoneal biopsy and subsequent pathological or microbiologic confirmation. ${ }^{57-60}$ Less invasive imaging techniques, such as ultrasound and computed tomography, can also initially be used to detect abdominal changes common in PTB, such as ascites (free or loculated), lymphadenopathy, peritoneal thickening and nodules, adhesions, and fibrinous septations. ${ }^{61-63}$ Additionally, computed tomography can be combined with ${ }^{18} \mathrm{~F}$-fluorodeoxyglucose positron emission tomography to increase sensitivity in determining peritoneal thickening of unknown origin. ${ }^{64}$ Either computed tomography or ultrasound can be used to facilitate peritoneal needle biopsy or aspiration of ascitic fluid. ${ }^{65}$ Our recommended stepwise approach for the diagnosis of PTB is detailed in Fig. 3. 
Wu D.C. et al: Peritoneal tuberculosis: A review

Table 2. PTB medical treatment in those with liver disease

\begin{tabular}{|c|c|c|c|}
\hline $\begin{array}{l}\text { Concomitant } \\
\text { immunocompromising } \\
\text { conditions }\end{array}$ & Initial therapy & Continuation therapy & Comments \\
\hline No liver disease ${ }^{65}$ & $\begin{array}{l}2 \text { months of INH, RIF, PZA and EMB } \\
\text { given daily }^{\varphi}\end{array}$ & $\begin{array}{l}\text { INH and RIF daily for } \\
\text { at least an additional } 4 \\
\text { months }\end{array}$ & \\
\hline $\begin{array}{l}\text { No liver disease, } \\
\text { HIV+ on } \\
\text { antiretroviral } \\
\text { therapy }\end{array}$ & $\begin{array}{l}2 \text { months of INH, RIF, PZA and EMB } \\
\text { given daily }\end{array}$ & $\begin{array}{l}\text { INH and RIF daily for } \\
\text { at least an additional } 4 \\
\text { months }\end{array}$ & $\begin{array}{l}\text { As HIV patients are often on many } \\
\text { additional medications, caution } \\
\text { must be used when managing } \\
\text { possible drug-drug interactions } \\
\text { between HAART and TB therapy }\end{array}$ \\
\hline $\begin{array}{l}\text { No liver disease, } \\
\text { HIV+ not on } \\
\text { antiretroviral } \\
\text { therapy/ delayed } \\
\text { response to } \\
\text { therapy }\end{array}$ & $\begin{array}{l}2 \text { months of INH, RIF, PZA and EMB } \\
\text { given daily }\end{array}$ & $\begin{array}{l}\text { INH and RIF daily for } \\
\text { at least an additional } 7 \\
\text { months }\end{array}$ & \\
\hline Treatment failure ${ }^{70}$ & & & $\begin{array}{l}\text { Revision of therapy with at least } \\
\text { three unused medications with at a } \\
\text { minimum one injectable agent } \\
\text { while awaiting sensitivities }\end{array}$ \\
\hline \multirow{4}{*}{$\begin{array}{l}\text { Liver disease } \\
\text { present }{ }^{12}\end{array}$} & RIF, PZA and EMB for 6 months & & \\
\hline & INH, RIF, EMB for 2 months & $\begin{array}{l}\text { followed by INH and } \\
\text { RIF for another } \\
7 \text { months }\end{array}$ & \\
\hline & $\begin{array}{l}\text { RIF, EMB, a fluoroquinolone, } \\
\text { cycloserine/ injectable agents for } \\
12-18 \text { months }\end{array}$ & & \\
\hline & $\begin{array}{l}\text { SM, EMB, fluoroquinolone (e.g., } \\
\text { moxifloxacin), and another second- } \\
\text { line oral drug }\end{array}$ & & $\begin{array}{l}\text { Second-line agents: } \\
\text { fluoroquinolones, rifabutin, } \\
\text { ethionamide, amino salicylic acid, } \\
\text { cycloserine }\end{array}$ \\
\hline
\end{tabular}

${ }^{\varphi}$ While additional TB therapies have been found to be equally efficacious in cases of pulmonary disease, listed treatment regimens reflect those that have been trialed specifically in cases of abdominal tuberculosis.

Abbreviations: EMB, ethambutol; HAART, highly-active antiretroviral therapy; INH, isoniazid; PZA, pyrazinamide; RIF, rifampin; TB, tuberculosis.

\section{Treatment}

Treatment for PTB is pharmacologic, with the drug regimen consistent with that used for pulmonary TB. Currently, the five common first-line medications are isoniazid (INH), RIF, pyrazinamide, ethambutol, and streptomycin. Treatment duration consists of a four-drug regimen administered for 2 months, with continuation of treatment with RIF and INH for 4 or more months $\mathrm{s}^{12}$ (Table 2). Studies examining the efficacy of prolonged dual-agent continuation therapy for 6 months or greater have not shown increased efficacy compared to the standard 4-month regimen. ${ }^{66,67}$ Response to therapy in PTB is usually noted within the first 3 months of treatment and is guided by the resolution of presenting symptoms, such as ascites and normalization of laboratory values. ${ }^{12}$ Surgical intervention in PTB is reserved for cases exhibiting signs of bowel perforation, intestinal obstruction, fistulae, abscesses, and hemorrhage. ${ }^{15}$

For HIV-positive patients on antiretroviral therapy, the TB treatment regimen does not differ from the aforementioned drug regimen, barring any drug-drug interactions with the antiretroviral medications. For HIV-positive patients not on antiretroviral therapy at the time of PTB diagnosis or for those with a delayed response to therapy, it is recommended that the continuation phase of treatment be extended to 7 months. ${ }^{68}$

Hepatotoxicity ( $11 \%$ of cases) is the most common cause of TB therapy discontinuation among all infected patients treated with combinations of INH, RIF, and pyrazinamide. ${ }^{69}$ In those that do not have serious hepatic complications from TB treatment, asymptomatic elevations in liver enzymes, specifically aspartate aminotransferase (AST), may occur. Unless enzyme elevations increase to 5 times the normal limit or 3 times the normal limit in the setting of symptomatic liver dysfunction, the treatment should not be altered. ${ }^{12}$ However, if there is an increase in liver enzyme levels, the intervals between scheduled liver function testing should be shortened. Other markers of adverse effects of TB therapy include rising bilirubin and alkaline phosphatase levels. These should be closely monitored and further investigated 
Wu D.C. et al: Peritoneal tuberculosis: A review

for complicating causes, such as worsening TB dissemination and/or direct infection of the liver/gallbladder. If laboratory markers or symptoms are severe enough to warrant the temporary cessation of therapy, treatment should not be reinitiated until AST levels are below 2 times the normal threshold. Once the decision is made to restart therapy, RIF may be restarted followed by INH, pyrazinamide, and ethambutol at a week apart. ${ }^{12}$

Patients with baseline liver disease face potentially serious complications from PTB treatment. One study showed hepatotoxicity rates of $26 \%$ in a cohort with baseline liver disease treated with the standard quadruple-agent therapy with dualagent continuation therapy, while another cohort also with baseline liver disease and treated with INH, RIF, ethambutol and ofloxacin for 2 months followed by INH and RIF for 10 months, showed no hepatotoxicity. ${ }^{64}$ Importantly, both groups achieved $100 \%$ response to their respective therapies. While several alternative regimens have been proposed for patients with liver disease, there is no universally adopted treatment strategy at this time. ${ }^{70}$ Unfortunately, delay or failure to treat TB carries high mortality rates, with one study showing an overall mortality rate of $35 \%$ and a mortality rate in cirrhotics as high as $73 \% .^{71}$

Corticosteroids have been used in some studies as an adjuvant therapy during the treatment process of PTB, dating as far back as the 1960 's. ${ }^{72}$ The theory behind the use of corticosteroids revolves around the idea that they reduce the amount of peritoneal inflammation and fibrosis caused by the infection and ultimately prevent adhesions that can lead to intestinal obstruction. ${ }^{73}$ While some modest benefit has been noted in small-scale studies, corticosteroids have not been extensively studied in this capacity and their use in PTB is not regularly recommended.

\section{Conclusions}

PTB is a growing problem due to the rising rates of immune compromise among the global population. Unfortunately, the diagnosis of PTB is difficult to make given its nonspecific symptoms and presentation. While imaging may be helpful in some presenting cases, paracentesis with fluid analysis remains paramount for diagnostic work-up. Although newer molecular biologic diagnostic techniques, such as PCR or ligase chain reaction, have shown significant promise, at present they are limited by their high false positive rates. Ultimately, there is no single laboratory test that can be used to consistently confirm the diagnosis of PTB, and at this time invasive studies, such as laparoscopy with peritoneal biopsy and subsequent histological or microbiologic confirmation, remain the gold standard for diagnosis.

Treatment of PTB depends on the severity of the disease, condition of the adaptive immune system, and baseline liver function. The antibiotic regimen for cases of uncomplicated PTB does not differ significantly from that of pulmonary TB. In cases of complicated PTB, such as in patients with HIV, an extended duration of therapy of at least 7 months is indicated. Due to the hepatoxicity of the agents used to treat PTB, liver function should be monitored throughout the course of antibiotic use, with treatment cessation only indicated in patients without signs of liver dysfunction who experience liver enzyme elevations 5 times the normal limit or in those with signs of liver dysfunction and elevated liver enzymes 3 times the normal limit.

\section{Conflict of interest}

The authors have no conflict of interests related to this publication.

\section{Author contributions}

Wrote the manuscript (DCW, LDA), and developed the idea for the article and critically revised it (GYW).

\section{References}

[1] World Health Organization. Global tuberculosis report 2017. Available from: https://www.who.int/tb/publications/global_report/gtbr2017_main_text. pdf.

[2] Shakil AO, Korula J, Kanel GC, Murray NG, Reynolds TB. Diagnostic features of tuberculous peritonitis in the absence and presence of chronic liver disease: a case control study. Am J Med 1996;100:179-185. doi: 10.1016/S0002-9343 (97) $89456-9$

[3] Chow KM, Chow VC, Szeto CC. Indication for peritoneal biopsy in tuberculous peritonitis. Am J Surg 2003;185:567-573. doi: 10.1016/S0002-9610(03) 00079-5.

[4] Centers for Disease Control and Prevention. Reported Tuberculosis in the United States, 2016. Available from: https://www.cdc.gov/tb/statistics/ reports/2016/.

[5] Farías Llamas OA, López Ramírez MK, Morales Amezcua JM, Medina Quintana $M$, Buonocunto Vázquez G, Ruiz Chávez IE, et al. Peritoneal and intestinal tuberculosis: an ancestral disease that poses new challenges in the technological era. Case report and review of the literature. Rev Gastroenterol Mex 2005;70:169-179.

[6] Corbett EL, Watt CJ, Walker N, Maher D, Williams BG, Raviglione MC, et al. The growing burden of tuberculosis: global trends and interactions with the HIV epidemic. Arch Intern Med 2003;163:1009-1021. doi: 10.1001/ archinte.163.9.1009.

[7] Bhargava DK, Shriniwas, Chopra P, Nijhawan S, Dasarathy S, Kushwaha AK. Peritoneal tuberculosis: laparoscopic patterns and its diagnostic accuracy. Am J Gastroenterol 1992;87:109-112.

[8] Huang B, Cui, Ren Y, Han B, Yang P, Zhao X. Comparison between laparoscopy and laboratory tests for the diagnosis of tuberculous peritonitis Turk J Med Sci 2018;48:711-715. doi: 10.3906/sag-1512-147.

[9] Suntur BM, Kuşçu F. Pooled analysis of 163 published tuberculous peritonitis cases from Turkey. Turk J Med Sci 2018;48:311-317. doi: 10.3906/sag1701-32.

[10] Shi XC, Zhang LF, Zhang YQ, Liu XQ, Fei G]. Clinical and laboratory diagnosis of intestinal tuberculosis. Chin Med J (Engl) 2016;129:1330-1333. doi: 10. 4103/0366-6999.182840.

[11] Abdelaal A, Alfkey R, Abdelaziem S, Abunada M, Alfaky A, Ibrahim WH, et al. Role of laparoscopic peritoneal biopsy in the diagnosis of peritoneal tuberculosis. A seven-year experience. Chirurgia (Bucur) 2014;109:330-334.

[12] Sanai FM, Bzeizi KI. Systematic review: tuberculous peritonitis-presenting features, diagnostic strategies and treatment. Aliment Pharmacol Ther 2005;22:685-700. doi: 10.1111/j.1365-2036.2005.02645.x.

[13] Uzunkoy A, Harma M, Harma M. Diagnosis of abdominal tuberculosis: experience from 11 cases and review of the literature. World J Gastroenterol 2004;10:3647-3649. doi: 10.3748/wjg.v10.i24.3647.

[14] Mehta JB, Dutt A, Harvill L, Mathews KM. Epidemiology of extrapulmonary tuberculosis. A comparative analysis with pre-AIDS era. Chest 1991;99: 1134-1138. doi: 10.1378/chest.99.5.1134.

[15] Tang LC, Cho HK, Wong Taam VC. Atypical presentation of female genital tract tuberculosis. Eur J Obstet Gynecol Reprod Biol 1984;17:355-363. doi: 10.1016/0028-2243(84)90115-1.

[16] Vaid U, Kane GC. Tuberculous peritonitis. Microbiol Spectr 2017;5. doi: 10. 1128/microbiolspec.TNMI7-0006-2016.

[17] Braun MM, Byers RH, Heyward WL, Ciesielski CA, Bloch AB, Berkelman RL, et al. Acquired immunodeficiency syndrome and extrapulmonary tuberculosis in the United States. Arch Intern Med 1990;150:1913-1916. doi: 10. 1001/archinte. 1990.00390200097018.

[18] Pornprasert S, Leechanachai P, Klinbuayaem V, Leenasirimakul P, Promping $C$, Inta $\mathrm{P}$, et al. Unmasking tuberculosis-associated immune reconstitution inflammatory syndrome in HIV-1 infection after antiretroviral therapy. Asian Pac J Allergy Immunol 2010;28:206-209. doi: 10.1310/hct1002-88.

[19] Schluger NW, Rom WN. The host immune response to tuberculosis. Am J Respir Crit Care Med 1998;157:679-691. doi: 10.1164/ajrccm.157.3.9708002.

[20] Verhave JC, van Altena R, Wijnands MJ, Roerdink HT. Tuberculous peritonitis during infliximab therapy. Neth J Med 2008;66:77-80. 
[21] Finlay DG, Szauter K, Raju GS, Snyder N. Tuberculous peritonitis. Am J Gastroenterol 2005;100:1624-1625. doi: 10.1111/j.1572-0241.2005. 50006_8. $\times$.

[22] Roth S, Delmont E, Heudier P, Kaphan R, Cua E, Castela J, et al. Anti-TNF alpha monoclonal antibodies (infliximab) and tuberculosis: apropos of 3 cases. Rev Med Interne 2002;23:312-316. doi: 10.1016/S0248-8663(01) 00556-2.

[23] Antolín J, Azahara M, Hernández C, Blanco M, Mao L, Cigüenza R. Tuberculous peritonitis after treatment with adalimumab. Scand J Infect Dis 2008; 40:677-678. doi: 10.1080/00365540701877320.

[24] Gutiérrez-Macías A, Lizarralde-Palacios E, Martínez-Odriozola P, Miguel-de la Villa $F$. Tuberculous peritonitis in a patient with rheumatoid arthritis treated with adalimumab. Clin Rheumatol 2007;26:452-453. doi: 10.1007/s10067005-0164-3.

[25] Sanches I, Carvalho A, Duarte R. Who are the patients with extrapulmonary tuberculosis? Rev Port Pneumol (2006) 2015;21:90-93. doi: 10.1016/j. rppnen.2014.06.010.

[26] Chou CH, Ho MW, Ho CM, Lin PC, Weng CY, Chen TC, et al. Abdominal tuberculosis in adult: 10-year experience in a teaching hospital in central Taiwan. J Microbiol Immunol Infect 2010;43:395-400. doi: 10.1016/S1684-1182(10) 60062-X.

[27] Talwani R, Horvath JA. Tuberculous peritonitis in patients undergoing continuous ambulatory peritoneal dialysis: case report and review. Clin Infect Dis 2000;31:70-75. doi: 10.1086/313919.

[28] Cho Y], Lee SM, Yoo CG, Kim YW, Han SK, Shim YS, et al. Clinical characteristics of tuberculosis in patients with liver cirrhosis. Respirology $2007 ; 12$ : 401-405. doi: 10.1111/j.1440-1843.2007.01069.x

[29] Schirren CA, Jung MC, Zachoval R, Diepolder H, Hoffmann R, Riethmüller G, et al. Analysis of $\mathrm{T}$ cell activation pathways in patients with liver cirrhosis, impaired delayed hypersensitivity and other T cell-dependent functions. Clin Exp Immunol 1997;108:144-150. doi: 10.1046/j.1365-2249.1997. d01-985.x

[30] Weng SF, Hsu CH, Lirn ML, Huang CL. Extrapulmonary tuberculosis: a study comparing diabetic and nondiabetic patients. Exp Clin Endocrinol Diabetes 2009;117:305-307. doi: 10.1055/s-0028-1128124.

[31] Alim MA, Sikder S, Bridson TL, Rush CM, Govan BL, Ketheesan N. Antimycobacterial function of macrophages is impaired in a diet induced model of type 2 diabetes. Tuberculosis (Edinb) 2017;102:47-54. doi: 10.1016/j. tube.2016.12.002.

[32] Struijk DG. Peritoneal dialysis in Western Countries. Kidney Dis (Basel) 2015;1:157-164. doi: 10.1159/000437286.

[33] Rohit A, Abraham G. Peritoneal dialysis related peritonitis due to Mycobacterium spp.: A case report and review of literature. J Epidemiol Glob Health 2016;6:243-248. doi: 10.1016/j.jegh.2016.06.005.

[34] Saleh MA, Ramadan MM, Arram EO. Toll-like receptor-2 Arg753GIn and Arg677Trp polymorphisms and susceptibility to pulmonary and peritoneal tuberculosis. APMIS 2017;125:558-564. doi: 10.1111/apm.12680.

[35] Fan L, Chen Z, Hao XH, Hu ZY, Xiao HP. Interferon-gamma release assays for the diagnosis of extrapulmonary tuberculosis: a systematic review and meta-analysis. FEMS Immunol Med Microbiol 2012;65:456-466. doi: 10. 1111/j.1574-695X.2012.00972.x.

[36] Azghay M, Bouchaud $O$, Mechaï F, Nicaise P, Fain O, Stirnemann J. Utility of QuantiFERON-TB Gold In-Tube assay in adult, pulmonary and extrapulmonary, active tuberculosis diagnosis. Int J Infect Dis 2016;44:25-30. doi: 10.1016/j.ijid.2016.01.004.

[37] Manohar A, Simjee AE, Haffejee AA, Pettengell KE. Symptoms and investigative findings in 145 patients with tuberculous peritonitis diagnosed by peritoneoscopy and biopsy over a five year period. Gut 1990;31:11301132. doi: 10.1136/gut.31.10.1130.

[38] Fei GJ, Zhang LF, Shu HJ. Values of different laboratory diagnostic approaches for tuberculous peritonitis. Zhongguo Yi Xue Ke Xue Yuan Xue Bao 2018;40:534-538. doi: 10.3881/j.issn.1000-503X.10516.

[39] Lui SL, Tang S, Li FK, Choy BY, Chan TM, Lo WK, et al. Tuberculosis infection in Chinese patients undergoing continuous ambulatory peritoneal dialysis. Am J Kidney Dis 2001;38:1055-1060. doi: 10.1053/ajkd.2001.28599.

[40] Zhou XX, Liu YL, Zhai K, Shi HZ, Tong ZH. Body fluid interferon- $\gamma$ release assay for diagnosis of extrapulmonary tuberculosis in adults: A systematic review and meta-analysis. Sci Rep 2015;5:15284. doi: 10.1038/srep15284.

[41] Lui SL, Lo CY, Choy BY, Chan TM, Lo WK, Cheng IK. Optimal treatment and long-term outcome of tuberculous peritonitis complicating continuous ambulatory peritoneal dialysis. Am J Kidney Dis 1996;28:747-751. doi: $10.1016 / \mathrm{S} 0272-6386(96) 90259-0$.

[42] Boyer TD. Diagnosis and management of cirrhotic ascites. In: Zakim D, Boyer TD, eds. Hepatology: A Textbook of Liver Disease. 4th edition. Philadelphia, USA: W.B. Saunders, 2003:631-658.

[43] Runyon BA, Montano AA, Akriviadis EA, Antillon MR, Irving MA, McHutchison JG. The serum-ascites albumin gradient is superior to the exudatetransudate concept in the differential diagnosis of ascites. Ann Intern Med 1992;117:215-220. doi: 10.7326/0003-4819-117-3-215.
[44] Demir K, Okten A, Kaymakoglu S, Dincer D, Besisik F, Cevikbas U, et al. Tuberculous peritonitis-reports of 26 cases, detailing diagnostic and therapeutic problems. Eur J Gastroenterol Hepatol 2001;13:581-585. doi: 10.1097/00042737-200105000-00019.

[45] Tong H, Tai Y, Ye C, Wu H, Zhang LH, Gao JH, et al. Carbohydrate antigen 125 and carcinoembryonic antigen in the differentiation of tuberculous peritonitis and peritonitis carcinomatosa. Oncotarget 2017;8:78068-78075. doi: 10.18632/oncotarget.17355.

[46] Xiao WB, Liu YL. Elevation of serum and ascites cancer antigen 125 levels in patients with liver cirrhosis. J Gastroenterol Hepatol 2003;18:1315-1316. doi: $10.1046 / j .1440-1746.2003 .03180 . x$.

[47] Martinez-Navio JM, Casanova V, Pacheco R, Naval-Macabuhay I, Climent N, Garcia $F$, et al. Adenosine deaminase potentiates the generation of effector, memory, and regulatory CD4+ T cells. J Leukoc Biol 2011;89: 127-136. doi: 10.1189/jlb.1009696.

[48] Saleh MA, Hammad E, Ramadan MM, Abd El-Rahman A, Enein AF. Use of adenosine deaminase measurements and QuantiFERON in the rapid diagnosis of tuberculous peritonitis. J Med Microbiol 2012;61:514-519. doi: $10.1099 / j m m .0 .035121-0$.

[49] Pimkina E, Zablockis R, Nikolayevskyy V, Danila E, Davidaviciene E. The Xpert ${ }^{\circledR}$ MTB/RIF assay in routine diagnosis of pulmonary tuberculosis: A multicentre study in Lithuania. Respir Med 2015;109:1484-1489. doi: 10. 1016/j.rmed.2015.07.006.

[50] Denkinger CM, Schumacher SG, Boehme CC, Dendukuri N, Pai M, Steingart KR. Xpert MTB/RIF assay for the diagnosis of extrapulmonary tuberculosis: a systematic review and meta-analysis. Eur Respir J 2014;44:435-446. doi: $10.1183 / 09031936.00007814$.

[51] Kohli M, Schiller I, Dendukuri N, Dheda K, Denkinger CM, Schumacher SG, et al. Xpert ${ }^{\circledR}$ MTB/RIF assay for extrapulmonary tuberculosis and rifampicin resistance. Cochrane Database Syst Rev 2018;8:CD012768. doi: 10.1002/ 14651858.CD012768.pub2.

[52] Sah AK, Joshi B, Khadka DK, Gupta BP, Adhikari A, Singh SK, et al. Comparative study of GeneXpert MTB/RIF assay and multiplex PCR assay for direct detection of mycobacterium tuberculosis in suspected pulmonary tuberculosis patients. Curr Microbiol 2017;74:1026-1032. doi: 10.1007/s00284-0171279-x.

[53] Raj A, Singh N, Gupta KB, Chaudhary D, Yadav A, Chaudhary A, et al. Comparative evaluation of several gene targets for designing a multiplex-PCR for an early diagnosis of extrapulmonary tuberculosis. Yonsei Med J 2016;57: 88-96. doi: 10.3349/ymj.2016.57.1.88.

[54] Hallur V, Sharma M, Sethi S, Sharma K, Mewara A, Dhatwalia S, et al. Development and evaluation of multiplex PCR in rapid diagnosis of abdominal tuberculosis. Diagn Microbiol Infect Dis 2013;76:51-55. doi: 10.1016/j.diagmicrobio.2013.02.022.

[55] Vadwai V, Shetty A, Rodrigues C. Using likelihood ratios to estimate diagnostic accuracy of a novel multiplex nested PCR in extra-pulmonary tuberculosis. Int J Tuberc Lung Dis 2012;16:240-247. doi: 10.5588/ijtld.11.0322.

[56] Schwake L, von Herbay A, Junghanss T, Stremmel W, Mueller M. Peritoneal tuberculosis with negative polymerase chain reaction results: report of two cases. Scand J Gastroenterol 2003;38:221-224.

[57] Dervisoglu E, Sayan M, Sengul E, Yilmaz A. Rapid diagnosis of Mycobacterium tuberculous peritonitis with real-time $P C R$ in a peritoneal dialysis patient. APMIS 2006;114:656-658. doi: 10.1111/j.1600-0463.2006. apm_456. $\times$.

[58] Muroni M, Rouet A, Brocheriou I, Houry S. Abdominal tuberculosis: utility of laparoscopy in the correct diagnosis. J Gastrointest Surg 2015;19:981-983. doi: 10.1007/s11605-015-2753-z.

[59] Guirat A, Affes N, Rejab H, Trigui H, Ben Amar M, Mzali R. Role of laparoscopy in the diagnosis of peritoneal tuberculosis in endemic areas. Med Sante Trop 2015;25:87-91. doi: 10.1684/mst.2014.0420.

[60] Akhan O, Demirkazik FB, Demirkazik A, Gülekon N, Eryilmaz M, Unsal M, et al. Tuberculous peritonitis: ultrasonic diagnosis. J Clin Ultrasound 1990;18: 711-714. doi: 10.1002/jcu.1990.18.9.711.

[61] von Hahn T, Bange FC, Westhaus S, Rifai K, Attia D, Manns M, et al. Ultrasound presentation of abdominal tuberculosis in a German tertiary care center. Scand J Gastroenterol 2014;49:184-190. doi: 10.3109/00365521. 2013.865258.

[62] Kedar RP, Shah PP, Shivde RS, Malde HM. Sonographic findings in gastrointestinal and peritoneal tuberculosis. Clin Radiol 1994;49:24-29. doi: 10. 1016/s0009-9260(05)82909-5.

[63] Charoensak A, Nantavithya P, Apisarnthanarak P. Abdominal CT findings to distinguish between tuberculous peritonitis and peritoneal carcinomatosis. J Med Assoc Thai 2012;95:1449-1456.

[64] Chen R, Chen Y, Liu L, Zhou X, Liu J, Huang G. The role of 18F-FDG PET/CT in the evaluation of peritoneal thickening of undetermined origin. Medicine (Baltimore) 2016;95:e3023. doi: 10.1097/MD.0000000000003023.

[65] Allah MH, Salama ZA, El-Hindawy A, Al Kady N. Role of peritoneal ultrasonography and ultrasound-guided fine needle aspiration cytology/biopsy of extravisceral masses in the diagnosis of ascites of undetermined origin. Arab J Gastroenterol 2012;13:116-124. doi: 10.1016/j.ajg.2012.08.004. 
[66] Jullien $S$, Jain $S$, Ryan $H$, Ahuja $V$. Six-month therapy for abdominal tuberculosis. Cochrane Database Syst Rev 2016;11:CD012163. doi: 10. 1002/14651858.CD012163.pub2.

[67] Makharia GK, Ghoshal UC, Ramakrishna BS, Agnihotri A, Ahuja V, Chowdhury $\mathrm{SD}$, et al. Intermittent directly observed therapy for abdomina tuberculosis: A multicenter randomized controlled trial comparing 6 months versus 9 months of therapy. Clin Infect Dis 2015;61:750-757. doi: $10.1093 /$ cid/civ376.

[68] Centers for Disease Control and Prevention. Treatment of LTBI and TB for persons with HIV. Available from: https://www.cdc.gov/tb/topic/treatment/tbhiv.htm.

[69] Ramappa V Aithal GP. Hepatotoxicity related to anti-tuberculosis drugs: Mechanisms and management. J Clin Exp Hepatol 2013;3:37-49. doi: 10. 1016/j.jceh.2012.12.001.

[70] Blumberg HM, Burman W], Chaisson RE, Daley CL, Etkind SC, Friedman LN et al. American Thoracic Society/Centers for Disease Control and Preventio$\mathrm{n} /$ Infectious Diseases Society of America: treatment of tuberculosis. Am J Respir Crit Care Med 2003;167:603-662. doi: 10.1164/rccm.167.4.603.

[71] Chow KM, Chow VC, Hung LC, Wong SM, Szeto CC. Tuberculous peritonitis associated mortality is high among patients waiting for the results of mycobacterial cultures of ascitic fluid samples. Clin Infect Dis 2002;35: 409-413. doi: 10.1086/341898.

[72] Horne NW. A critical evaluation of corticosteroids in tuberculosis. Bibl Tuberc $1966 ; 22: 1-54$

[73] Alrajhi AA, Halim MA, al-Hokail A, Alrabiah F, al-Omran K. Corticosteroid treatment of peritoneal tuberculosis. Clin Infect Dis 1998;27:52-56. doi: $10.1086 / 514627$

[74] Debi U, Ravisankar V, Prasad KK, Sinha SK, Sharma AK. Abdominal tuberculosis of the gastrointestinal tract: revisited. World J Gastroenterol 2014; 20:14831-14840. doi: 10.3748/wjg.v20.i40.14831.
[75] Singh MM, Bhargava AN, Jain KP. Tuberculous peritonitis. An evaluation of pathogenetic mechanisms, diagnostic procedures and therapeutic measures. N Engl J Med 1969;281:1091-1094. doi: 10.1056/NEJM1969111 32812003

[76] Diwany M, Gabr MK. Treatment of tuberculous peritonitis in children with streptomycin. J Egypt Med Assoc 1952;35:376-388.

[77] Hammon L. The statistics of tuberculous peritonitis from the clinica records of the Johns-Hopkins Hospital. Bull Johns Hopkins Hosp 1908; 19:256

[78] Faulkner RL, Everett HS. Tuberculous peritonitis: A statistical and clinica study of one hundred eighty-seven cases. Arch Surg 1930;20:664-690. doi: 10.1001/archsurg.1930.01150100124008

[79] McPhedran H, Peacock G. Tuberculous peritonitis. A report of 21 case treated at St. Michael's Hospital during past 5 years. CMAJ 1933;29:617.

[80] Stubenbord JG, Spies J. Tuberculous peritonitis: An analysis of 257 cases Surg Gynec Obst 1938;67:269.

[81] Barrow DW. Tuberculous peritonitis. South Med J 1943;36:646-650. doi: 10 . 1097/00007611-194309000-00009.

[82] Brown TM, Wichelhausen RH, Sadusk JF Jr. Tuberculous peritonitis treated with streptomycin. Am J Med 1949;6:506. doi: 10.1016/0002-9343(49) 90225-9.

[83] Kahrs T. Tuberculous peritonitis; a follow-up study of 169 cases. Tubercle 1952;33:132-138. doi: 10.1016/s0041-3879(52)80081-9.

[84] Hughes HJ, Carr DT, Geraci JE. Tuberculous peritonitis: a review of 34 cases with emphasis on the diagnostic aspects. Dis Chest 1960;38:42-50. doi: 10 . 1378/chest.38.1.42.

[85] Dineeen $P$, Homan WP, Grafe WR. Tuberculous peritonitis: 43 years expereince in diagnosis and treatment. Ann Surg 1976;184:717-722. doi: 10.1097/00000658-197612000-00010 